\title{
Moral-related Variables and Mental Health: A Correlational Study
}

\author{
AlirezaAzimpour \\ Assistant Professor of Psychology, Department of Psychology, Faculty of Human Sciences, Salman Farsi University \\ of Kazerun, Kazerun, Iran, Email: a.azimpour@kazerunsfu.ac.ir (*Corresponding Author)
}

\begin{abstract}
The existence of a positive relationship between moral activities and mental health has been established in some studies; however, there are different types of moral-related variables as well as mental health-related ones. The present study is aimed at examining the probable relationship between them. A body of 212 university freshmen completed questionnaires about different mental health-related variables and moral-related ones. After controlling the effects of social desirability and lie/nonsense responses, the relationship between moral-related and mental health-related variables was investigated through partial correlation. The findings indicated that mental healthrelated variables differently related to moral-related ones. Among the moral-related variables anonymous pro-social behavior and overall pro-social moral reasoning related to more numbers of mental health-related variables. Also, among the mental health-related variables perfectionism and social support related to a greater number of moralrelated variables. The findings were discussed in light of previous studies and the definitions of the variables. Keywords: Mental health; Pro-social behaviors; Pro-social moral reasoning; Psychopathological variables.
\end{abstract}

\section{Introduction}

Moral or pro-social behaviors are almost considered as evolutionally useful behaviors (Piliavin \& Charng, 1990). In addition, many studies have confirmed that pro-social tendencies correlate to health, mental health or some mental health-related variables (Barber, Eccles, \& Stone, 2001; Crocker, Canevello, Breines, \& Flynn, 2010; Erickson \& Abelson, 2012; Moen, DempsterMcClain, \& Williams Jr, 1992; Thoits \& Hewitt, 2001; Weinstein \& Ryan, 2010). Then some researchers hint to reciprocal effects between pro-social behaviors and health (Crocker et al., 2010; Thoits \& Hewitt, 2001; Weinstein \& Ryan, 2010). However, some dimensions of morality may have different implications for mental health. The philosopher, Nietzsche (1884-1900) believed that a type of morality (i.e. slave morality) is deleterious of human being's flourishing (Holmes, 2014). Eisenberg and Fabes (1998) showed the linkage of compliant pro-social behaviors and non-assertiveness among children. Similarly, Weinstein and Ryan (2010) found that controlled helping did not have positive outcomes for well-being. Also, it has been found that hyper-morality positively relates to obsessive-compulsive disorder (Franklin, McNally, \& Riemann, 2009; Gwilliam, Wells, \& Cartwright-Hatton, 2004; Nelson, Abramowitz, Whiteside, $\&$ Deacon, 2006).

To study the relationship of different moral-related and mental health-related variables, the present study considered a variety of moral-related variables; empathy. Several types of prosocial behavior include public pro-social behavior (i.e. helping in front of others), compliant prosocial behavior (i.e. helping in response to a verbal or nonverbal request), emotional pro-social behavior (i.e. helping under emotionally evocative circumstances), dire pro-social behavior (i.e. helping in crisis or emergency situations), anonymous pro-social behavior (i.e. helping performed without knowledge of whom helped), and altruistic pro-social behavior (i.e. helping without anticipating the rewards from external sources) (Carlo \& Randall, 2002). Types of prosocial moral reasoning include Hedonistic (i.e. reasoning according to the gains to self), approval-oriented (i.e. reasoning according to others' approval), needs-oriented (i.e. orientation 
to the physical, material, or psychological needs of the other person), stereotypic (i.e. reasoning according to stereotyped images of good or bad) and internalized pro-social moral reasoning (i.e. reasoning according to sympathy, perspective tacking, internalized effects or abstract internalized reasoning)(Carlo, Eisenberg, \& Knight, 1992). Two types of moral identity are internalization (i.e. degree to which the moral traits are central to the self-concept) and symbolization (i.e. degree to which the moral traits are reflected in the respondent's actions in the world) (Aquino \& Reed, 2002).

Several mental health-related variables in this study, according to model of Yaghobi, Poursharifi, and Akbari Zardkhaneh (2014), included positive emotions, well-being, depression, anxiety, obsessive-compulsive tendencies, social anxiety, sleep disturbances, suicidal tendencies, educational depression, total psychopathology, family atmosphere, religiosity, perfectionism, self-efficacy and social support. Some relationships between the variables and some moralrelated variables have been confirmed in previous studies; the positive relationships of some moral-related variables to positive mood (Piliavin \& Charng, 1990), well-being (Thoits \& Hewitt, 2001), psychological satisfaction (Weinstein \& Ryan, 2010) overall mental health (Moen et al., 1992), self-esteem and educational graduation (Barber et al., 2001), religiosity (Azimpour, Naisi, Shehni, Arshadi, \& Beshlideh, 2014), perfectionism (Lutwak \& Ferrari, 1996) and obsessive-compulsive disorder (Franklin et al., 2009; Gwilliam et al., 2004; Nelson et al., 2006). Up to knowledge of the researcher, so far no study has addressed the relationships of these groups of variables.

\section{Material and Methods}

A body of 212 freshmen from Salman Farsi University of Kazerun (164 females, M of age: 18.99; SD of age: 1.16) participated voluntarily in 2014. To further motivate the students, they were told to receive their test results by Email. The measurement of moral-related variables and social desirability was conducted after classrooms in the first month of their first semester. Two or three weeks before it, the mental health of all freshman students had been measured by the counseling center of the university. The reason for considering freshman students as participants was the less interval between the mental health assessment (by concealing center) and the researcher's moral-related assessment; However, there was two or three weeks interval between them yet. It is worth mentioning that since data were collected by self-report measures, there was the probability of lie/nonsense or socially desirable responses. So both of social desirability and lie/nonsense responses (i.e. assessed by Pro-social Reasoning Objective Measure), were controlled through the partial correlation method.

\section{Measures}

Iranian National Mental Health Scale for students:The scale was developed by Poursharifi et al. (2012) and was later modified by Yaghobi et al. (2014). It has 93 items from responding scale of 1 (completely agreeable) to 6 (completely disagreeable). The scale has 3 dimensions: psychopathological dimension (depression: $\alpha=0.77$, anxiety: $\alpha=0.83$, obsession-compulsion: $\alpha=$ 0.70, social anxiety: $\alpha=0.81$, sleep disorder: $\alpha=0.76$ ), mental health-related dimension (academic depression: $\alpha=0.78$, academic anxiety: $\alpha=0.81$ family atmosphere: $\alpha=0.72$, perfectionism: $\alpha=0.59$ suicidal tendencies: $\alpha=0.69$, religiosity: $\alpha=0.86$; self-efficacy: $\alpha=0.82$, perceived social support: $\alpha=0.83$ ) and positive dimension (positive emotions: $\alpha=0.92$, well- 
being: $\alpha=0.77$ ). In addition to estimating reliability through internal consistency (Cronbach's $\alpha$ ), reliability and validity of the measure were also confirmed by confirmatory factor analysis, criterion-referenced validity and test-retest reliability (Yaghobi et al., 2014).

Pro-social Tendencies Measure (PTM): The measure has 23 items with a response scale ranging from 1 (does not describe me at all) to 5 (describes me greatly). It was developed by Carlo and Randall (2002). Later it was translated to Persian and validated on Iranian university students by (Azimpour, Neasi, Shehni-Yailagh, Arshadi, \& Beshlideh, 2012). The 6 types of prosocial behavior of the measure and the internal consistency (Cronbach's $\alpha$ ) of them in Azimpour et al. (2012b) validation are: altruistic: 0.84 , anonymous: 0.85 , dire: 0.63 , emotional: 0.75 , compliant: 0.80 and public: 0.78. (Azimpour et al., 2012)criticized the validity of the altruistic subscale in Persian replica after studying convergent and divergent validity of the subscales.

Adult Version of the Pro-social Reasoning Objective Measure (PROM-R): The measure developed by Carlo et al. (1992) was translated into Persian and next it was validated on Iranian university students byAzimpour, Neasi, Shehni-Yailagh, Arshadi, and Beshlide (2013). PROM-R consists of several stories that include moral predicaments and also three choices for each story that are listed about what the character ought to do. The scoring is based on selecting the level of importance (from 1 to 7 ) of the reasons that are listed under any main story about why the behavior of the character. The reasons for each of the stories are according to the five types of pro-social moral reasoning. Also, there is a meaningless item (reason) under any stories for assessing the lie/nonsense responses. The measure can be scored in the form of overall score of pro-social reasoning or can be scored in the form of scores for ratios of any five subscales of prosocial reasoning. The subscales of PRPM-R and their internal consistencies (Cronbach's $\alpha$ ) in Azimpour et al. (2013) was 0.81 for hedonistic, 0.92 for approval-oriented, 0.64 for needsoriented, 0.66 for stereotypic and 0.79 for internalized.

Self-importance of Moral Identity:This measure was developed by Aquino and Reed (2002). Azimpour et al. (2014) translated and validated it on Iranian university students. To administer the measure, participants should at first be asked to imagine a person who has some moral traits (e.g. caring, compassionate, fair, or friendly). Then they should answer 10 questions about these traits on a response scale ranging from 1 (Strongly Disagree) to 7 (Strongly Agree). It consists of two different subscales including internalization (the degree to which moral traits are central to the self-concept) and symbolization (the degree to which moral traits are reflected in the respondent's actions in the world) (Aquino \& Reed, 2002). In the study by Azimpour et al. (2014) Cronbach's $\alpha$ for the internalization and the symbolization were 0.79 and 0.78 , respectively.

Toronto empathy questionnaire: This questionnaire which was developed by Spreng, McKinnon, Mar, and Levine (2009)consists of 16 items on a response scale ranging from 0 (never) to 4 (always). It was translated to Persian and validated on Iranian university students by Azimpour et al. (2012). The internal consistency of the measure was estimated to be 0.72 .

Marlowe-Crowne Social Desirability Scale: The 13-item version of this measure Reynolds (1982) with a response scale of 0 and 1 (true/false) was used. The measure was validated in different societies (Verardi et al., 2010). Persian translation and its validation were done by Najarian (cited by Najarian and Soudani, 2001).Azimpour et al. (2012) in the study of Iranian 
university students' sample reported internal consistency of 0.51 for this measure using KuderRichardson formula.

\section{Results}

Table 1 represents descriptive indices of the variables. The correlation between all variables after controlling the effects of social desirability and lie/nonsense responding was calculated by partial correlation method (Table 2). Hedonistic pro-social reasoning negatively related to self-efficacy (r: $-0.25, \mathrm{p}<0.01)$, social support (r: $-0.21, \mathrm{p}<0.05)$ and religiosity $(\mathrm{r}:-0.16, \mathrm{p}<0.1)$; However, it positively related to depression ( $\mathrm{r}: 0.19, \mathrm{p}<0.05)$, academic depression $(\mathrm{r}: 0.22, \mathrm{p}<0.05)$, suicidal tendencies ( $\mathrm{r}: 0.22, \mathrm{p}<0.05)$ and anxiety $(\mathrm{r}: 0.15, \mathrm{p}<0.1)$. Approval-oriented pro-social reasoning positively related to perfectionism ( $\mathrm{r}: 0.18, \mathrm{p}<0.05)$, social anxiety $(\mathrm{r}: 0.15, \mathrm{p}<0.1)$, obsessive compulsive tendencies ( $\mathrm{r}: 0.17, \mathrm{p}<0.1)$ and total psychopathology $(\mathrm{r}: 0.15, \mathrm{p}<0.1)$. Needs-oriented pro-social reasoning negatively related to anxiety ( $\mathrm{r}:-0.19, \mathrm{p}<0.05)$, obsessive compulsive tendencies $(\mathrm{r}:-0.19, \mathrm{p}<0.05)$ and total psychopathology $(\mathrm{r}:-0.19, \mathrm{p}<0.05)$. But stereotypic pro-social reasoning only had positive relationship with social support (r: $0.17, \mathrm{p}<$ 0.1 ). While Internalized pro-social reasoning positively related to social support ( $\mathrm{r}: 0.16, \mathrm{p}<$ 0.1 ), it negatively related to perfectionism ( $\mathrm{r}:-0.18, \mathrm{p}<0.05)$, obsessive compulsive tendencies ( $\mathrm{r}:-0.21, \mathrm{p}<0.05$ ), depression ( $\mathrm{r}:-0.2, \mathrm{p}<0.05$ ) academic depression ( $\mathrm{r}:-0.18, \mathrm{p}<0.05$ ), suicidal tendencies ( $\mathrm{r}:-0.21, \mathrm{p}<0.05)$, total psychopathology $(\mathrm{r}:-0.18, \mathrm{p}<0.05)$ and social anxiety $(\mathrm{r}$ : $0.16, \mathrm{p}<0.1)$. This pattern of correlations was similar to that of overall pro-social reasoning and the variables (rs for social support: 0.17 , for perfectionism: -0.16, for social anxiety: -0.17, for obsession compulsion: -0.23 , for depression: -0.2 , for academic depression: -0.18 , for suicidal tendency: -0.21 and for total psychopathology: -0.21) with the difference that the significance of its relationships to perfectionism was borderline $(\mathrm{p}<0.1)$. There was also a negative relationship with anxiety ( $\mathrm{r}:-0.15, \mathrm{p}<0.1)$.

Public pro-social behavior had positive correlation only with perfectionism $(\mathrm{r}: 0.15, \mathrm{p}<0.1)$ and compliant pro-social behavior had positive correlation with perfectionism $(\mathrm{r}: 0.33, \mathrm{p}<0.01)$ and well-being ( $\mathrm{r}: 0.2, \mathrm{p}<0.05$ ). Dire pro-social behavior positively correlated with positive emotions (r: 0.22, p < 0.05), well-being (r: 0.24, p < 0.01), self-efficacy $(\mathrm{r}: 0.31, \mathrm{p}<0.01)$ and perfectionism (r: 0.29, p < 0.01). It also negatively correlated with depression $(r:-0.29, p<0.01)$, academic depression ( $\mathrm{r}:-0.18, \mathrm{p}<0.05)$ and total psychopathology ( $\mathrm{r}:-0.16, \mathrm{p}<0.1)$. Emotional pro-social behavior positively correlated with perfectionism (r: $0.27, \mathrm{p}<0.01)$ well-being $(\mathrm{r}$ : $0.16, \mathrm{p}<0.1)$ and self-efficacy $(\mathrm{r}: 0.16, \mathrm{p}<0.1)$ but negatively related to suicidal tendencies $(\mathrm{r}$ : $0.18, \mathrm{p}<0.1)$. Anonymous pro-social behavior positively related to well-being $(\mathrm{r}: 0.25, \mathrm{p}<$ 0.01 ), self-efficacy ( $\mathrm{r}: 0.28, \mathrm{p}<0.01$ ), social support (r: $0.25, \mathrm{p}<0.01)$, religiosity $(\mathrm{r}: 0.42, \mathrm{p}<$ 0.01 ) perfectionism ( $\mathrm{r}: 0.19, \mathrm{p}<0.05$ ), family atmosphere ( $\mathrm{r}: 0.18, \mathrm{p}<0.05$ ) and positive emotions ( $\mathrm{r}: 0.16, \mathrm{p}<0.1)$. It also negatively related to suicidal tendencies $(\mathrm{r}:-0.23, \mathrm{p}<0.01$ ), obsessive compulsive tendencies ( $\mathrm{r}:-0.22, \mathrm{p}<0.05)$, depression ( $\mathrm{r}:-0.22, \mathrm{p}<0.05)$, academic depression ( $\mathrm{r}:-0.28, \mathrm{p}<0.05)$, sleep disorder $(\mathrm{r}:-0.17, \mathrm{p}<0.1)$ and total psychopathology (r: $0.16, \mathrm{p}<0.1)$. Altruistic pro-social behavior only negatively related to perfectionism ( $\mathrm{r}:-0.27, \mathrm{p}$ $<0.01$ ), positive emotions ( $\mathrm{r}:-0.22, \mathrm{p}<0.05)$ and well-being ( $\mathrm{r}:-0.2, \mathrm{p}<0.05)$. Internalization subscale of moral identity positively related to social support (r: $0.26, \mathrm{p}<0.01)$, perfectionism ( $\mathrm{r}$ : $0.24 ; \mathrm{p}<0.01$ ), religiosity (r: 0.38, $\mathrm{p}<0.01$ ), positive emotion $(\mathrm{r}: 0.22, \mathrm{p}<0.05$ ) and family 
atmosphere (r: $0.21, \mathrm{p}<0.05)$. Symbolization subscale of moral identity positively correlated to well-being ( $\mathrm{r}: 0.24, \mathrm{p}<0.01$ ), perfectionism ( $\mathrm{r}: 0.26, \mathrm{p}<0.01$ ), religiosity $(\mathrm{r}: 0.23, \mathrm{p}<0.01$ ), family atmosphere (r: 0.29, p < 0.01), self-efficacy (r: 0.21, p <0.05), and social support (r: 0.17 , $\mathrm{p}<0.1)$. Empathy positively related to well-being ( $\mathrm{r}: 0.2, \mathrm{p}<0.05)$, social support $(\mathrm{r}: 0.23, \mathrm{p}<$ 0.05 ), perfectionism (r: $0.19, \mathrm{p}<0.05)$, positive emotion $(\mathrm{r}: 0.16, \mathrm{p}<0.1)$, religiosity $(\mathrm{r}: 0.17, \mathrm{p}$ $<0.1)$, and negatively related to suicidal tendencies $(\mathrm{r}:-0.22, \mathrm{p}<0.05)$.

Table1.Descriptive statistics of the variables

\begin{tabular}{|c|c|c|c|c|c|c|c|c|}
\hline variable & mean & SD & variable & mean & SD & variable & mean & SD \\
\hline 1 & 25.08 & 6.8 & 12 & 13.21 & 5.73 & 23 & 30.24 & 4.52 \\
\hline 2 & 28.52 & 4.45 & 13 & 15.28 & 5.8 & 24 & 20.2 & 6.08 \\
\hline 3 & 27.27 & 5.14 & 14 & 14.73 & 6.52 & 25 & 6.32 & 2.7 \\
\hline 4 & 26.96 & 7.12 & 15 & 17.47 & 7.42 & 26 & 7.1 & 2.08 \\
\hline 5 & 28 & 4.27 & 16 & 76.19 & 23.22 & 27 & 10.06 & 2.92 \\
\hline 6 & 27.16 & 6.93 & 17 & 23.94 & 3.55 & 28 & 14.26 & 3.85 \\
\hline 7 & 29.11 & 5.34 & 18 & 16.25 & 4.62 & 29 & 18.23 & 5.01 \\
\hline 8 & 15.96 & 6.49 & 19 & 14.94 & 2.30 & 30 & 20.01 & 3.52 \\
\hline 9 & 19.88 & 7.68 & 20 & 13.89 & 2.16 & 31 & 49.66 & 5.62 \\
\hline 10 & 16.18 & 6.64 & 21 & 30.98 & 4.11 & 32 & 9.21 & 2.92 \\
\hline 11 & 15.09 & 4.85 & 22 & 190.79 & 9.5 & 33 & 8.09 & 2.31 \\
\hline
\end{tabular}

Note: 1- positive emotions, 2- well-being, 3- self efficacy, 4- social support, 5- perfectionism, 6- religiosity, 7- family atmosphere, 8- anxiety, 9academic anxiety, 10- social anxiety, 11- obsession-compulsion, 12- depression, 13- academic depression, 14- sleep disorder, 15- suicidal tendencies, 16- total psychopathology, 17- hedonistic pro-social reasoning, 18- approval-oriented pro-social reasoning, 19- need-oriented prosocial reasoning, 20- stereotypic pro-social reasoning, 21- internalized pro-social behavior, 22- pro-social reasoning (totally), 23- internalization of moral identity, 24- symbolization of moral identity, 25- public pro-social behavior, 26- compliant pro-social behavior, 27- dire pro-social behavior, 28- emotional pro-social behavior, 29- anonymous pro-social behavior, 30- altruistic pro-social behavior, 31- empathy, 32- lie/nonsense responding, 33- social desirability.

Table2.Correlations between moral-related variables and mental health-related variables after parting lie/nonsense responding and social desirability

\begin{tabular}{|c|c|c|c|c|c|c|c|c|c|c|c|c|c|c|c|}
\hline & 17 & 18 & 19 & 20 & 21 & 22 & 23 & 24 & 25 & 26 & 27 & 28 & 29 & 30 & 31 \\
\hline 1 & -0.14 & 0.08 & 0.14 & -0.04 & $\begin{array}{l}-0.03 \\
\end{array}$ & 0.00 & $0.22^{*}$ & 0.12 & -0.02 & 0.12 & $0.22^{*}$ & 0.07 & $0.16^{\approx}$ & $-0.22^{*}$ & $0.16^{\approx}$ \\
\hline 2 & -0.07 & 0.01 & 0.09 & -0.05 & $\begin{array}{l}0.02 \\
\end{array}$ & 0.03 & 0.14 & $0.24^{*+1}$ & 0.13 & $0.2^{*}$ & $0.24^{* * *}$ & $0.16^{\approx}$ & $0.25^{* *}$ & $-0.2^{*}$ & $0.2^{*}$ \\
\hline 3 & $-0.25^{* *}$ & 0.08 & 0.07 & 0.03 & 0.075 & 0.09 & 0.08 & $0.21^{*}$ & 0.04 & 0.15 & $0.31^{* *}$ & $0.16^{\approx}$ & $0.28^{* * 1}$ & -0.14 & -0.013 \\
\hline 4 & $-0.21^{*}$ & $\begin{array}{l}-.04 \\
\end{array}$ & $\begin{array}{c}-0.02 \\
\end{array}$ & $0.17^{\approx}$ & $0.16^{\approx}$ & $0.17^{\approx}$ & $0.26^{* *}$ & $0.17^{\approx}$ & -0.04 & 0.12 & 0.08 & 0.12 & $0.25^{* * *}$ & 0.01 & $0.23^{*}$ \\
\hline 5 & 0.00 & $0.18^{*}$ & 0.04 & -0.1 & $-0.18^{*}$ & $-0.16^{\approx}$ & $0.24^{* *}$ & $0.26^{* * *}$ & $0.15^{\approx}$ & $0.33^{* * 1}$ & $0.29^{* * *}$ & $0.27^{* *}$ & $0.19^{*}$ & $-0.27^{*}$ & $0.19^{*}$ \\
\hline 6 & $-0.16^{\tilde{z}}$ & 0.00 & 0.01 & 0.04 & 0.1 & 0.1 & $0.38^{* *}$ & $0.23^{* *}$ & -0.1 & 0.13 & 0.14 & 0.14 & $0.42^{* * *}$ & -0.02 & $0.17^{\approx}$ \\
\hline 7 & $\begin{array}{l}-0.1 \\
\end{array}$ & 0.01 & 0.14 & 0.01 & 0.01 & 0.05 & $0.21^{*}$ & $0.29^{* * *}$ & 0.01 & 0.07 & 0.11 & 0.00 & $0.18^{*}$ & -0.06 & 0.11 \\
\hline 8 & $0.15^{\approx}$ & 0.09 & $-0.19^{*}$ & -0.03 & -0.11 & $-0.15^{\approx}$ & 0.13 & 0.02 & 0.09 & 0.1 & -0.14 & $\begin{array}{c}-0.03 \\
\end{array}$ & -0.03 & 0.00 & 0.02 \\
\hline 9 & 0.07 & 0.09 & -0.1 & -0.01 & -0.01 & -0.11 & 0.1 & 0.08 & -0.01 & 0.07 & -0.11 & 0.02 & -0.07 & -0.02 & -0.02 \\
\hline 10 & 0.06 & $0.15^{\approx}$ & -0.07 & -0.06 & $-0.16^{\approx}$ & $-0.17^{\approx}$ & 0.14 & 0.09 & 0.00 & 0.00 & -0.12 & $\begin{array}{l}-0.03 \\
\end{array}$ & $\begin{array}{l}-0.02 \\
\end{array}$ & 0.03 & $\begin{array}{l}-0.1 \\
\end{array}$ \\
\hline 11 & 0.14 & $0.17^{\approx}$ & $-0.19^{*}$ & 0.02 & $-0.21^{*}$ & $-0.23^{*}$ & 0.04 & 0.00 & -0.04 & 0.00 & 0.00 & \begin{tabular}{|c|}
-0.11 \\
\end{tabular} & $-0.22^{*}$ & 0.06 & 0.07 \\
\hline 12 & $0.19^{*}$ & 0.08 & -0.12 & 0.02 & $-0.2^{2}$ & $-0.2^{*}$ & -0.13 & -0.08 & 0.08 & -0.07 & $-0.19^{*}$ & -0.15 & $-0.22^{*}$ & 0.02 & -0.11 \\
\hline 13 & $0.22^{*}$ & 0.03 & -0.08 & 0.00 & $-0.18^{*}$ & $-0.18^{*}$ & 0.02 & -0.01 & -0.01 & -0.01 & $-0.18^{*}$ & \begin{tabular}{c|}
-0.08 \\
\end{tabular} & $-0.28^{*}$ & 0.11 & -0.09 \\
\hline 14 & 0.00 & 0.09 & -0.14 & 0.06 & -0.04 & -0.06 & 0.01 & 0.02 & 0.08 & 0.02 & -0.14 & -0.12 & $-0.17^{\approx}$ & -0.03 & 0.03 \\
\hline 15 & $0.22^{*}$ & 0.06 & -0.12 & 0.03 & $-0.21^{*}$ & $-0.21^{*}$ & -0.13 & -0.13 & 0.08 & -0.11 & -0.17 & $-0.18^{*}$ & $-0.23^{* *}$ & 0.05 & $-0.22^{*}$ \\
\hline 16 & 0.14 & $0.15^{\approx}$ & $-0.19^{*}$ & 0.00 & $-0.18^{*}$ & $-0.21^{*}$ & 0.08 & 0.02 & 0.06 & 0.02 & $-0.16^{\approx}$ & -0.11 & $-0.16^{\approx}$ & 0.02 & -0.06 \\
\hline
\end{tabular}

Notes: 1- positive emotions, 2- well-being, 3- self efficacy, 4- social support, 5- perfectionism, 6- religiosity, 7- family atmosphere, 8- anxiety, 9- academic anxiety, 10- social anxiety, 11- obsession-compulsion, 12- depression, 13- academic depression, 14- sleep disorder, 15- suicidal tendencies, 16- total psychopathology, 17- hedonistic pro-social reasoning, 18approval-oriented pro-social reasoning, 19- need-oriented pro-social reasoning, 20- stereotypic pro-social reasoning, 21internalized pro-social behavior 22- pro-social reasoning (totally), 23- internalization of moral identity, 24- symbolization of moral identity, 25- public pro-social behavior, 26- compliant pro-social behavior, 27- dire pro-social behavior, 28- emotional prosocial behavior, 29- anonymous pro-social behavior, 30- altruistic pro-social behavior, 31- empathy, $(* *: \mathrm{p}<0.01, *: \mathrm{p}<0.05, \approx$ : $\mathrm{p}<0.1$ ). 


\section{Discussion}

Negative relationships of Hedonistic reasoning and some positive constructs (self-efficacy, social support) and positive relationships of it, and the psychopathological constructs (depression, academic depression, and suicidal tendencies) was in the coordination of Ingram's review (Ingram, 1990), that self-focused attention is a characteristic of many mental disorders, particularly depression. Similarly, Empathy related positively more with positive variables (wellbeing, social support, family atmosphere) and also negatively related to suicidal tendencies. Indeed against the commonsense, it can be imagined that over-attention to egoistic reasoning or emotion can even lead to self-destructive actions such as suicide.

Approval-oriented pro-social reasoning (such as emotional pro-social behavior) only positively related to perfectionism. Perfectionism is the tendency to have high goals and standards (Flett, Hewitt, \& Dyck, 1989); perhaps it can be supposed that such goals and standards are external goals that originate from other people. Then the individuals with higher perfectionism should have higher approval-oriented reasoning and higher emotional reaction to do according to other's demands.

Although, the stereotypic pro-social reasoning was considered as developmentally high-level reasoning by Carlo et al. (1992) in relationships of it and any mental health-related variables suggest that the stereotypic claims cannot be considered as originally high-level moral reasoning. Needs-oriented pro-social reasoning as morally high-level reasoning, it had negative relationships with total psychopathology, obsessive-compulsive tendencies, and anxiety(Carlo et al., 1992). Also, Internalized pro-social reasoning (and overall pro-social reasoning) as morally and developmentally highest kind of pro-social reasoning, negatively related to total psychopathology, suicidal tendencies, depression, academic depression, obsessive-compulsive tendencies, and perfectionism(Carlo et al., 1992). Because these high-level types of moral reasoning did not relate positively to other positive variables, it seems that higher pro-social reasoning can be seen as a prophylactic variable than emitting the well-being or positive feeling. Regarding the conceptual definition of compliant pro-social behavior (Carlo \& Randall, 2002) as well as findings of Eisenberg and Fabes (1998), it can be predicted that some pathological variable especially social anxiety would positively relate to this behavior; nevertheless, it only positively related to perfectionism and well-being. However, anonymous pro-social behavior positively related to all positive mental health-related variables (except positive emotions) and perfectionism and also negatively related to many psychopathological variables (except anxiety, social anxiety, academic anxiety, sleep disorder, and total psychopathology).

Although altruistic behavior was considered as a highly moral behavior (Carlo \& Randall, 2002), surprisingly it negatively related to self-efficacy, well-being, and perfectionism. Perhaps such surprising relationships can be attributed to the weak validity of altruistic subscale in Iranian replica of Pro-social Tendencies Measure (Azimpour et al., 2012).

Dire pro-social behavior positively related to some positive variables (positive emotions, wellbeing, self-efficacy) and perfectionism. It also negatively related to some psychopathological variables (depression and academic depression). Furthermore, the symbolization and internalization of moral identity both positively related to perfectionism and positive variables such as social support, religiosity, and family atmosphere. Internalization also positively related 
to positive emotions, and symbolization also related positively to well-being, social support, and self-efficacy. Considering these findings and also the non-significant negative relationship of both moral identity subscales with psychopathological variables, it can be discussed that moral identity is more related to the positive variables and it is not a prophylactic variable.

Among the moral-related variables, anonymous pro-social behavior and overall pro-social reasoning related to a greater number of mental health-related variables. Pro-social reasoning related negatively to psychopathological variables but anonymous pro-social behavior related both negatively to psychopathological variables and positively to positive variables. From the mental health-related variables perfectionism related to a larger number of moral-related variables. The pattern of relationships for perfectionism was interesting. Whereas it is negatively related to overall pro-social reasoning (and internalized reasoning), is positively related to some other moral-related variables. It confirms that perfectionism has multi-dimensional implications for different aspects of morality.

Despite the studies which have confirmed the positive relationship of obsessive-compulsive disorder and moral-related variables (Franklin et al., 2009; Gwilliam et al., 2004; Nelson et al., 2006), no any highly moral variables had any positive relationship with obsessive-compulsive tendencies or any other psychopathological variables. Perhaps it can be attributed to using a normal sample of freshmen students in this study. The present study just studied the correlations and causality explanation was considered only as a probability. Then as a recommendation for future research, some experimental studies can be deemed in which mutual effects of mental health-related variables and different moral-related variables that were claimed by some researches (Crocker et al., 2010; Thoits \& Hewitt, 2001; Weinstein \& Ryan, 2010) would be examined.

\section{References}

Aquino, K., \& Reed, I. (2002). The self-importance of moral identity. Journal of Personality and Social Psychology, 83(6), 1423.

Azimpour, A., Naisi, A., Shehni, Y. M., Arshadi, N., \& Beshlideh, K. (2014). Validation the measure of "the self-importance of moral identity" on university students. Journal of personality and individual differences, 3(4), 19-38.

Azimpour, A., Neasi, A., Shehni-Yailagh, M., Arshadi, N., \& Beshlide, K. (2013). Assessment prosocial moral reasoning on Iranian: evaluation the measurement models and validation the measure of Prosocial Moral Reasoning on Iranian university students. Journal of Life Science and Biomedicine, 3(1), 10-15.

Azimpour, A., Neasi, A., Shehni-Yailagh, M., Arshadi, N., \& Beshlideh, K. (2012). Designing and testing a model of important precedents of prosocial behavior in student of Shahid Chamran University. J Psychol Achieve, 19(3), 15-44.

Barber, B. L., Eccles, J. S., \& Stone, M. R. (2001). Whatever happened to the jock, the brain, and the princess? Young adult pathways linked to adolescent activity involvement and social identity. Journal of adolescent research, 16(5), 429-455.

Carlo, G., Eisenberg, N., \& Knight, G. P. (1992). An objective measure of adolescents' prosocial moral reasoning. Journal of research on adolescence, 2(4), 331-349. 
Carlo, G., \& Randall, B. A. (2002). The development of a measure of prosocial behaviors for late adolescents. Journal of youth and adolescence, 31(1), 31-44.

Crocker, J., Canevello, A., Breines, J. G., \& Flynn, H. (2010). Interpersonal goals and change in anxiety and dysphoria in first-semester college students. Journal of Personality and Social Psychology, 98(6), 1009.

Eisenberg, N., \& Fabes, R. (1998). Prosocial development. I: Damon, W. \& Eisenberg, N.(red) Handbook of Child Psychology: John Wiley.

Erickson, T. M., \& Abelson, J. L. (2012). Even the downhearted may be uplifted: Moral elevation in the daily life of clinically depressed and anxious adults. Journal of Social and Clinical Psychology, 31(7), 707-728.

Flett, G. L., Hewitt, P. L., \& Dyck, D. G. (1989). Self-oriented perfectionism, neuroticism and anxiety. Personality and Individual Differences, 10(7), 731-735.

Franklin, S. A., McNally, R. J., \& Riemann, B. C. (2009). Moral reasoning in obsessivecompulsive disorder. Journal of anxiety disorders, 23(5), 575-577.

Gwilliam, P., Wells, A., \& Cartwright-Hatton, S. (2004). Dose meta-cognition or responsibility predict obsessive-compulsive symptoms: a test of the metacognitive model. Clinical Psychology \& Psychotherapy: An International Journal of Theory \& Practice, 11(2), 137144.

Holmes, R. L. (2014). Basic moral philosophy: Nelson Education.

Ingram, R. E. (1990). Self-focused attention in clinical disorders: review and a conceptual model. Psychological bulletin, 107(2), 156.

Lutwak, N., \& Ferrari, J. R. (1996). Moral affect and cognitive processes: Differentiating shame from guilt among men and women. Personality and Individual Differences, 21(6), 891-896.

Moen, P., Dempster-McClain, D., \& Williams Jr, R. M. (1992). Successful aging: A life-course perspective on women's multiple roles and health. American Journal of Sociology, 97(6), 1612-1638.

Najarian. B. \& Soudani, M. (2001). Construction and Validation of a scale for the measurement of reality distortion. Journal of education and psychology, Shahid Chamran university of Ahvaz, 3 (8), 99-114.

Nelson, E. A., Abramowitz, J. S., Whiteside, S. P., \& Deacon, B. J. (2006). Scrupulosity in patients with obsessive-compulsive disorder: Relationship to clinical and cognitive phenomena. Journal of anxiety disorders, 20(8), 1071-1086.

Piliavin, J. A., \& Charng, H.-W. (1990). Altruism: A review of recent theory and research. Annual review of sociology, 16(1), 27-65.

Reynolds, W. M. (1982). Development of reliable and valid short forms of the Marlowe-Crowne Social Desirability Scale. Journal of Clinical Psychology, 38(1), 119-125.

Spreng, R. N., McKinnon, M. C., Mar, R. A., \& Levine, B. (2009). The Toronto Empathy Questionnaire: Scale development and initial validation of a factor-analytic solution to multiple empathy measures. Journal of personality assessment, 91(1), 62-71.

Thoits, P. A., \& Hewitt, L. N. (2001). Volunteer work and well-being. Journal of health and social behavior, 115-131.

Verardi, S., Dahourou, D., Ah-Kion, J., Bhowon, U., Tseung, C. N., Amoussou-Yeye, D., ... . Mbodji, M. (2010). Psychometric properties of the Marlowe-Crowne social desirability scale 
in eight African countries and Switzerland. Journal of Cross-Cultural Psychology, 41(1), 1934.

Weinstein, N., \& Ryan, R. M. (2010). When helping helps: Autonomous motivation for prosocial behavior and its influence on well-being for the helper and recipient. Journal of Personality and Social Psychology, 98(2), 222.

Yaghobi, H., Poursharifi, H., \& Akbari Zardkhaneh, S. (2014). Manual, scoring and interpretation of national Mental Health Scale for students. Tehran: publication of Jahade daneshgahi. 